prosecute original research or clinical study in some department of medicine. Applicants must give such evidence of capacity for the work which they desire to prosecute as shall appear satisfactory to the Faculty of Medicine. The holders of such grants must furnish reports of their work either during the prosecution of, or at the close of, their studies. Further information regarding these research grants may be obtained from the Secretary of the University, to whom all applications must be forwarded.

It is proposed to give opportunities for advanced clinical work to graduates at the Royal Victoria Hospital, Belfast. The clinical rooms will afford excellent facilities for carrying on such work. For further information and particulars application should be made to Dr. R. J. Johnstone, honorary secretary, medical staff, 17, University-square, Belfast, or at the hospital.

Cork.-At University College a post-graduate course has been held hitherto for the Diploma in Pablic Health, including Chemistry, by Professor A. E. Dixon; Putlic Heaith, by Mr. D. Donovan, public health officer of the city

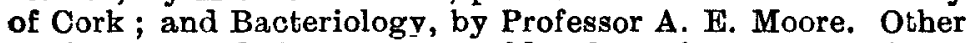
professors and lecturers would also give post-graduate courses if requested to do so. No post-graduate courses have up to the present been held at the hospitals. All the College and hospital courses are open to men and women students.

Dublin -Trinity College and the Royal College of Surgeons each make arrangements for a course of postgraduate instruction in the year. The course arranged by Trinity College is held in September-October and occupies three weeks. Instruction is usually given in the following 11 subjects : Medicine, Surgery, Gynæcology, Diseases of Eye, Diseases of Throat, Nose, and Ear, Diseases of Skin, Pathology, Anatomy, Physiology, $X$ Ray Work, and Cystoscopy. One or two teachers deal with each subject, and a detailed syllabus is published beforehand, care being taken to choose matters of particular interest at the time. The courses in pathology, anatomy, and physiology are designed with special bearings on clinical problems. The classes are held in the School of Physic, Trinity College, and in Sir Patrick Dun's, the Adelaide, the Royal City of Dublin, the Rotunda, and the Royal Victoria Eye and Ear Hospitals. Arrangements are made by which a limited number of members of the class can reside in College rooms and dine on commons, at an inclusive cost of $£ 11 s$. per week. The composite fee for the entire course is $£ 55 s$. The autumn course for 1911 will begin on Sept. 25th and end on Oct. 14th. Full particulars can be obtained from the honorary secretary, 27, Lower Fitzwilliam-street, Dublin.

The post-graduate courses arranged under the auspices of the President and Council of the Royal College of Surgeons in Ireland have hitherto proved a most gratifying success. The object of these courses is to render available the whole of the clinical material in the city for the post-graduate student, so that he may see as much as possible during the brief time at his disposal. With this object in view the ten general hospitals of the city are included (Richmond, Jervis-street, Adelaide, St. Vincent's, Dr. Steevens', Mater Misericordix, Meath, Mercer's, Royal City of Dublin, and Sir Patrick Dan's), and also the various hospitals which are devoted to "specialties." The opportunities afforded are shown by a glance at the list of special subjects and the institutions where they are respectively cultivated: Skin, Adelaide Hospital ; Eye and Ear, Royal Victoria Eye and Ear Hospital ; Throat and Nose, Mater Misericordiz Hospital and Sir Patrick Dan's Hospital ; Gynæcology, Rotunda Hospital, Coombe Hospital, and National Maternity Hospital ; X Ray and Light Therapeutics, Meath Hospital and Sir Patrick Dun's Hospital ; Pathology and Bacteriology, Richmond, Whitworth, and Hardwicke Hospitals, Mate Misericordiæ Hospital, Meath Hospital, and School of Surgery, Royal College of Surgeons ; Diseases of Children, Orthopædic Hospital, Temple-street Hospital, and Harcourtstreet Hospital ; Lunacy, Richmond Districi Lunatic Asylum; Anæsthetics, Dental Hospital ; Cadaver Operations, Professors at Schools of Surgery, R.C.S I. ; Anatomy, Professor of Anatomy, R.C.S.I. ; Sanitary Science, Professor of Hygiene, R.C.S.I. 'The course for 1911 will begin on Monday, Sept. 18th, and will terminate on Oct. 10th following. Fee for course, inclusive of all, $£ 55 s$. Full details regarding the course can be obtained from, and all applications are to be addressed to, the Professor of Anatomy, Royal College of Surgeons in Ireland. A list of addresses of apartments and hotels, which have agreed to modified rates for pupils while passing through the course, can be obtained by application at the Royal College of Surgeons.

In addition to the special courses detailed above, arrangements can be made at the various laboratories and hospitals for individual post.graduate work. In particular the practice of the maternity hospitals, the Rotunda, the Coombe, and the National Lying-in, is made much use of by graduates from all parts of the world.

All courses are open to women practitioners on the same terms as to men.

\section{THE TRAINING OF CADETS IN THE MEDICAL UNIT OF THE CAMBRIDGE UNIVERSITY OFFICERS' TRAINING CORPS.}

BY H. Buckley Roderick, M.A., M.D. Cantab., UNIYERSTTY DEMONSTRATOR OF SURGERY; OFFICER COMMANDIXG MEDICAT UNIT, C.V.o.T.C.

THE medical unit of the Cambridge University Officers? Traiving Corps $h$ as been established three years, and the scheme of training of the cadets, which at first, of necessity, was of an experimental nature, has now taken definite shape and resolved itself into :-(A) Individual instruction, consisting (1) of lectures and demonstrations, and (2) of drills; and (B) the exercising of the medical unit as a whole in the field.

\section{A. Individual Instruotion.}

1. Lectures and denonstrations.-O Owing to the multifarious lectures and demonstrations which the medical student is compelled to attend in the course of his ordinary studies there is little time or inclination left for much instruction of this nature. It has, therefore, been found sufficient to confine this branch of the training to one lecture a week. During the Michaelmas term a course of lectures and demonstrations is given in first aid, dressing and healing of wounds, antiseptic principles, preparation of a patient, instruments, \&c., for operation, and the application of triangular and roller bandages. The Lent term is devoted to lectures on military hygiene and sanitation and the general organisation of the Army and of Field Medical Units and the work of Field Medical Units in the field. Owing to the nearness of the triposes and M.B. Fxaminations no lectures are given during the Easter term.

2. Drills. - During the Michaelmas and Lent terms squad, company, and stretcher drills are held every week at times to suit the convenience of cadets. During the Easter term the work is confined to early morning ( 7 A. M.) parades twice a week. The annual inspection of the corps takes place in the Easter term and necessitates some practice in ceremonial drill. Otherwise nothing more is attempted during the Easter term.

B. The Exeroising of the Medioal Unit as a Whole in the Fiold.

This has resolved itself into the holding of two field days a term-i e., Michaelmas and Lent. In one a small scheme is worked out in detail, whilst in the other an extensive scheme is worked out in skeleton. In the former the unit takes the field as a section of a field ambulance and falling in with the general scheme of the corps the tent division establishes a dressing station on a suitable site near the scene of operations, subsequently converting it into a tent division company, pitching the operating tent, bell tents, and bivouacs, and constructing trench kitchens, latrines, incinerators, and slop sinks. The bearer division search for, and attend to, the "wounded," on whom "tallies" are fixed stating the nature of the wound, and convey them on stretchers to the ambulance wagons at the wagon rendezvous and thence back to the dressing station. The cadets are thus made acquainted with the detailed work of a section of a field ambulance, which they, in fact, represent.

On the second field day in each term a more extensive scheme is attempted, and the unit is made to represent in skeleton perhaps three field ambulances (i.e., the medical establishment of a division) depending on the nature of the scheme. On these occasions the cadets parade with bicycles at the medical schools which represents the head quarters of the "administrative medical officer." Here they are informed of the "general idea" of the day's battle and receive their special orders and instruetions before proceeding to their respective localities. On tbese days 
Colonel .James, C.B., R A.M.C., of the War Office staff, and one or more other officers of experience act as umpires, and every member of the unit represents an officer with responsible duties to perform. Oa the completion of the operations the members of the unit reassemble at the medical schools, where each cadet makes his report, which is criticised by the umpires.

To illustrate the work done on these occasions a cadet is commanded to proceed to the scene of action and choose a site for a dressing station; he is instructed to take advantage of existing buildings for the harbouring of the wounded, to calculate the number of patients each building would hold, and to report as to the suitability of such buildings for the purpose. The accessibility to main roads and railway lines, and in the case of the latter the existence or not, and the capacity, of sidings for the loading of ambulance trains, are to be reported upon, and the cadet is to estimate the quantity and ascertain the quality of the water-supplies and the available food-supply in the district in the shape of cattle and sheep, fowls, milk, eggs, corn, \&c. He is also instructed to note the number of sacks and hurdles, and to estimate the quantity of straw available for the extemporising of stretchers and bedding, and the number of farm wagons, carts, and horses obtainable to supplement or relieve the ambulances for the conveyance of the wounded to the clearing hospital. He has also to calculate the number of wagons required to convey the estimated wounded under his charge and the probable time that would be taken in evacuating all his wounded.

From the experience gained in two such field days the cadet should be able to grasp both the detailed work of a section of a field ambulance and also the means employed in collecting, providing for, and evacuating a large number of casualties from an extensive field of battle to the clearing hospital.

The time at the disposal of the medical undergraduate to give to "soldiering" is very little after he has satisfied the requirements of his college tutor and college clabs, so that unless the work of the unit can be made interesting enough to form one of his recreations it is difficult to persuade him, on purely patriotic motives, that it is one of his duties to join the corps. It is therefore very satisfactory to be able to state that the medical unit is rapidly gaining in popularity, and that its members are drawn from the best all-round men in the colleges.

Thus the cadet, during the first years of his medical education, has the opportunity, by way of a recreation one may say, of gaining a practical insight into the detail of first aid in all its branches, into the technique of minor surgery, into the hygienic problems that arise in ordinary simple life, and into many other subjects not included in the medical curriculum. He is not likely to have such opportunities later in his career, as his time is indeed more than fully occupied.

It would seem that this simple training not only teaches the student how an organised body of men is managed and cared for, bat it instils into him the rudiments of a business training and business meth ds, together with an orderly and methodical way of dealing with problems of organisation which is invaluable to, but only too rarely found in, the average medical man. It also materially helps him to obtain a wider outlook of his own fature and a broader view of the objects of his studies in the earlier period of his career.

Instrdetion in Hospital Administration.The Metropolitan Asylums Board has instituted a three months' course of lectures and demonstrations in hospital administration at the North-Western Hospital and at the Grove Hospital, Tooting. At the North-Western Hospital the lectures will commence on Monday, Oct. 9th, and will be continued on successive Mondays ( 3 P.M.) and Thursdays (11 A.M.). At the Grove Hospital the lectures will commence on Wednesday, Oct. 4th, and will be continued on successive Saturdays (11 A M.) and Wednesdays ( 3 P.M.). The fee for the course is $£ 33 s$. In the case of each hospital the lectures and demonstrations on the two days in any one week will be identical. Students can attend on the day that best suits them, and they can join the class at any time provided they complete their attendance during the term beginning in January, 1912. The fee must be paid in advance to the clerk of the Metropolitan Asylums Board, Embankment, London, E. C.

\section{Aunnotations.}

$$
\text { "Ne quid nimis." }
$$

\section{THE POSTPONEMENT OF THE INTERNATIONAL CONGRESS ON TUBERCULOSIS.}

THE Organising Committee of the Seventh International Congress on Tuberculosis has issued a circular stating that the postponement of this Congress from September, 1911, to April, 1912, was desired by many foreign com. mittees, and is generally approved. The circular goes on to say that, according to the last number of $L a$ Tubercolosi, the official organ of the Congress, it appears that from June last the scientific and general organisation or preparation for the Congress was "in the best conditions." Nearly all the reports had arrived and many papers had been received and announced, says the circular, adding, "the postponement, however, will help to definitively coördinate the contributions from all nations, and ensure the most widespread coopperation of all the civilised world in the great scientific and humanitarian meeting to be held in Rome in April, 1912." It must be confessed that this is an unsatisfactory document. Had the committee plainly stated that the danger of cholera was such that it was thought on all accounts, and notwithstanding the great inconvenience that must ensue, more prudent to postpone the Congress, it is doubtful if a murmur would have arisen, and certainly on all sides the sincerest sympathy would have been expressed. As for reports and papers, a large number are always sent too late; and this does not in the least matter, for they are generally far too numerous to be read or discussed. Postponing the Congress, with all the counter orders this entails, has gravely complicated matters, and such an act seems justifiable only in the face of so grave an affair as the probable spread to Rome of the actual cholera epidemic. But little thought seems to have been given to those coming from far distant regions-Australasia, for instance-who, in order to arrive in time, must actually have started before the postponement was annonnced. But over and above this individual hardship the committee must have known that in September, 1912, the Fifteenth International Congress of Hygiene and Demography meets at Washington. There are no two congresses more closely allied. Those who attend the parent Congress of Hygiene also endeavour to assist at the Congress on Tuberculosis. The same sanitary reformers meet at these two congresses and their intercourse becomes more intimate and more useful. But how many will be able to afford the money and the time to go to Italy next spring and to the United States in the autumn of next year? Instead of being 12 months apart the congresses will be only six months apart, and this must be mutually injurious. If there is real danger of cholera of course these grave inconveniences cannot be helped; but if, as is suggested in the circular, it is merely to allow a committee more time to sort a few papers, then the postponement has been, we think, injudicious. This occurrence is a good illustration of the necessity for a permanent international committee in respect of all these congresses. At the meeting of the International Association of the Medical Press in Budapest two years ago it was maintained that such a committee should take in hand the organisation, not merely of medical congresses, but of congresses of the allied sciences. The object was to unify where possible and to prevent overlapping or clashing. Such a committee would have kept well before the organisers of the congress at Rome the fact that the congress at Washington was to follow shortly afterwards. If an international committee, having in view the interests of all the other congresses, had given its 